\title{
Design \& Analysis of Multiband Sierpenski Gasket Fractal Antenna using Iteration Method
}

\author{
Ch. Raghavendra, B.Pavan kalyan, K Vijaykrishna, A.Vamsikrishna
}

\begin{abstract}
Wireless communication systems require antennas of multiband support,small design dimensions and higher gain. To provide size reduction and better impedance matching, geometrical interpreted fractal antenna is suitable. This allows the antenna to operate at different frequencies. To rise performances with respect to bandwidth, gain and multiband resonance, an array can fulfil the requirements. This paper shows the design and simulation of the Sierpinski Gasket array for multiband applications ( $4 \mathrm{GHz}$ to $8 \mathrm{GHz}, 8 \mathrm{GHz}$ to $12 \mathrm{GHz}$ ) up to $4^{\text {th }}$ iteration. The fractal geometry for patch antenna is selected due to low cross polarization radiation and ease of fabrication. Sierpinski gasket is known by the name, Sierpinski triangle having triangular slots using mid-point geometry of the triangle. This array makes use of micro strip feed where FR4 epoxy is used as the dielectric substrate. A low profile dielectric is used to get the radiation in maximum amount. This antenna finds its uses in satellite communications and transmissions, Wi-Fi. The simulation is carried out by using High Frequency Structure Simulator HFSS V13 software for the proposed antenna.
\end{abstract}

Index terms: fractal antenna, sierpinski triangle, sierpinski gasket array.

\section{INTRODUCTION}

For wireless communication system, one of the most important component is antenna. overall system performance can be improved by the good design of the antenna .The rapid expansion of wireless technology over the recent years has led to increasing demand for small sized, low-cost and multiband operational antennas for use in commercial communications systems. Today's satellite, wireless and advanced military communication systems needs antennas of higher gain, higher performance, multiband support, low cost, wider bandwidth and conservatively minor design dimensions. To meet these required conditions researchers are looking for more modern antenna design concepts. Antennas are the major components of low-profile, conformal \& integrated wireless communication systems. Therefore, antenna miniaturizations desired in attaining an optimal design for wireless communications. It is known that as the antenna size reduces, it becomes inefficient because of its directivity, radiation resistance, bandwidth and gain. In the present-day scenario there is a reduction in the size of electronics system and a astonishing increase in the functionality. These requirements are fulfilled by the fractal antennas.

Revised Manuscript Received on December 30, 2019.

* Correspondence Author

Mr.Ch.Raghavendra, Assistant professor, V.R.Siddhartha Engineering College, Vijayawada.

K.Vijay krishna B.Tech, Electronics and Communication Engineering from V.R.Siddhartha Engineering College, Vijayawada

B.Pavan kalyan B.Tech, Electronics and Communication Engineering from V.R.Siddhartha Engineering College, Vijayawada

(C) The Authors. Published by Blue Eyes Intelligence Engineering and Sciences Publication (BEIESP). This is an open access article under the CC BY-NC-ND license (http://creativecommons.org/licenses/by-nc-nd/4.0/)
In the study of antennas, fractal antenna theory is a relatively new area. The term fractal means irregular or fragmented, the two meanings define fractal concept. It is a type of geometric shape which possess property of similarity. Fractal antennas are utilized in wide range of applications from communication system to medical system, primarily due to their low cost, conformability, simplicity, low profile, light weight, ease of integration and reproducibility with solid state device. The group of different types of geometries occupies a class of fractals to develop the electrical property. Electrical property means increase in resonant frequency band and reduction in size of antenna. Due to these additional features and advantages in multi -function and multi-standard wireless equipment. Multiband and wideband antennas are required in personal, small satellite communication systems, and other wireless applications. Some applications also require an antenna to be embedded into the airframe structure. The self-similar properties of certain fractals result in a multiband behaviour of the antennas while, the highly convoluted shape of these fractals makes possible the reduction in size. The term "fractal" has almost as many definitions as it does applications across various fields of study. One popular definition is "a rough or fragmented geometric shape that can be split into parts, each of which is (at least approximately) a reduced-size copy of the whole". In simpler terms, "fractal" is used to describe patterns with a self-similar nature.The concept of self-similar nature is also found that which defines "fractal antenna" as "A multiband antenna having a self-similar shape at several different scales". The modern multiband antenna developments are based upon the self-resemblance property of shapes of fractals. Fractals have no specific size or pattern. These are made by numerous repetitions of a single basic shape and are used to categorise a family of composite forms that possess an essential self-similarity and self-affinity in their structure. . A Self-affinity, is a reduction that reduces an image by several factors, horizontally and vertically A selfsimilar property means scaled down copies of itself, i.e., a reduction that reduces an image by same factors horizontally and vertically. Thus, it can offers extra flexibility in the design of antenna. The geometry of fractals provides a improved solution for this problem by the presence of its two major characteristics: self-similarity and space filling. So, fractal concepts have become an important approach for characterizing \& designing multiband and wideband antennas.

\section{FEEDING METHOD}

\section{PROBE FEED:}

Probe feed or coaxial feed method is used for nourishing Micro strip patch antennas. It is shown in Figure.1 and found that the outer conductor is coupled to the ground plane,

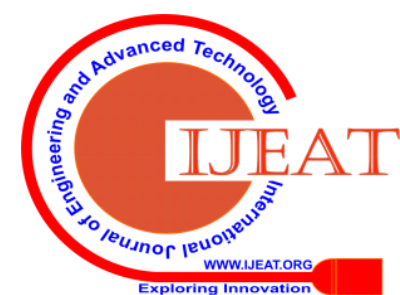


meanwhile the inner conductor of the coaxial connector is integrated to radiating patch. The most important advantage of this method is that there is no need to compare with its input impedance and the patch can be located inside a place of wanting to feed. The feed to make the process easier and less radiation is bogus.

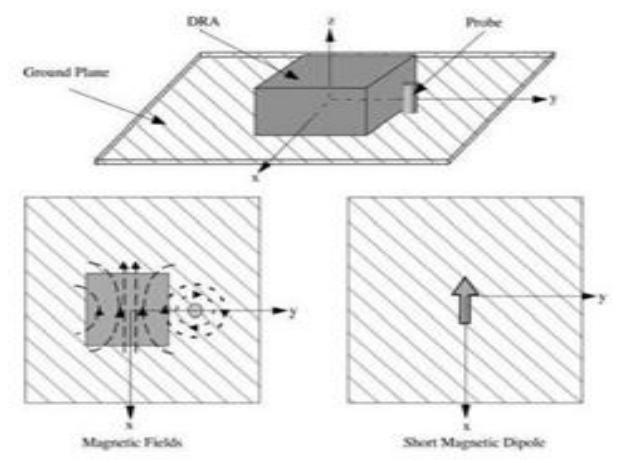

Fig:1.Probe feed

\section{ANTENNA DESIGN}

For the proposed antenna design resonant frequency $\left(f_{r}\right)$ is selected as $4 \mathrm{GHz}$. The substrate material used is FR4 glass epoxy material with thickness $1.6 \mathrm{~mm}$ and dielectric constant 4.4. The side length (se) of antenna's proposed design is calculated by using the below given expression and found that side length of the proposed design is equal to $0.0476 \mathrm{~m}$.

$$
f_{r}=\frac{2 c}{3 S_{e} \sqrt{\varepsilon_{r}}}
$$

Where $\mathrm{Se}=$ side length of triangular patch and $\mathrm{C}=$ velocity of light. The below figure. 2 shows the base geometry of the $0^{\text {th }}$ iteration. Now by connecting the mid points of base geometry, the middle triangle is eliminated. Then joint a circular geometry with rad ius identical to radius of incircle of smaller triangle at centroid of base triangle to form generation of the $1^{\text {st }}$ iteration. The $2^{\text {nd }}$ iteration geometry is obtained by cutting three triangles of same size from the $1^{\text {st }}$ iteration. Infinite times the process can be repetitive. The $4^{\text {th }}$ iteration geometry is as shown in the figure. 2 shows the proposed design and the stages of iteration process.

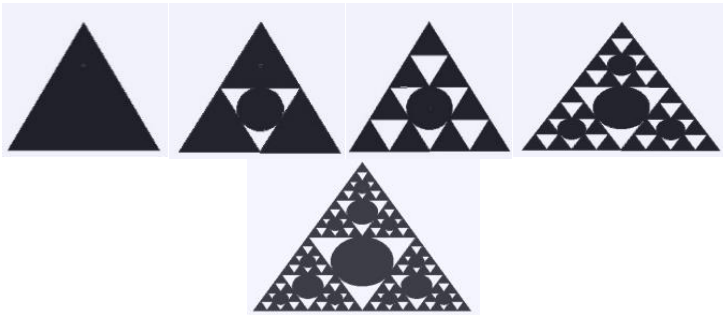

Fig:2. Iteration Process

Length of the ground plane is $50.88 \mathrm{~mm}$ and breadth is $57.27 \mathrm{~mm}$. Length of the substrate is material is $50.88 \mathrm{~mm}$,bredth is $57.22 \mathrm{~mm}$ and height is $1.6 \mathrm{~mm}$. To the patch, the geometry of fractals is applied such that generation of discontinuity takes place and additional current flows on the discontinuity part. To advance the outcomes, triangles are presented at the corner of triangular patch in $2^{\text {nd }}, 3^{\text {rd }}$ and $4^{\text {th }}$ iterations.

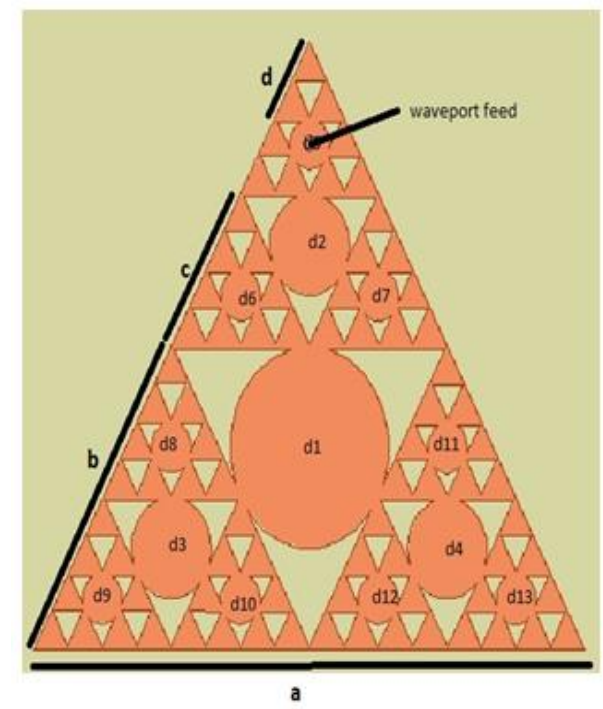

Fig:3.Geometry of proposed antenna

The triangular slots in the triangular patch is shown in above figure.3. The triangular patch lemgth is $47.67 \mathrm{~mm}$, the length of the second iterated triangle is $23.835 \mathrm{~mm}$, the length of the third iterated triangle is $5.95 \mathrm{~mm}$ and the length of the fourth iterated triangle is $2.975 \mathrm{~mm}$ respectively. The diameters of the circles are determined using the in circle method. The diameter of the biggest circle is $13.76 \mathrm{~mm}$, the diameter of the second biggest circle is $6.88 \mathrm{~mm}$ and the diameter of the last circle is $3.44 \mathrm{~mm}$.

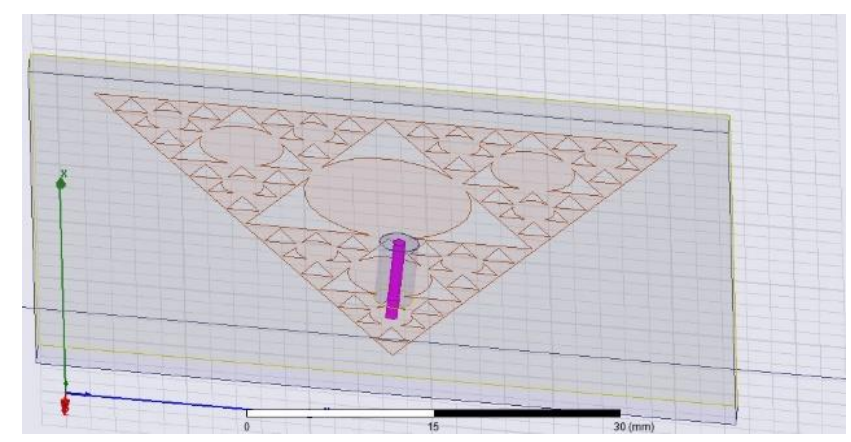

Fig:4. Probe feed bottom view

The wave port feed position is as shown in the figure. 4 at the centre of circle with diameter indicated as $\mathrm{d} 4$. The inner cylinder radius of wave port feed is $0.5 \mathrm{~mm}$, outer cylinder radius is $1.6 \mathrm{~mm}$. The two cylinders are coaxial as shown in figure.4. The material used of outer cylinder is vacuum and that of inner cylinder is 'pec'.

\section{SIMULATION RESULTS}

The wave port probe feeding is used to achieve accurate results for the proposed antenna. The location of the feed point is altered till improved results are obtained for return loss and VSWR at anticipated frequency location.

Published By:
Blue Eyes Intelligence Engineering \& Sciences Publication 


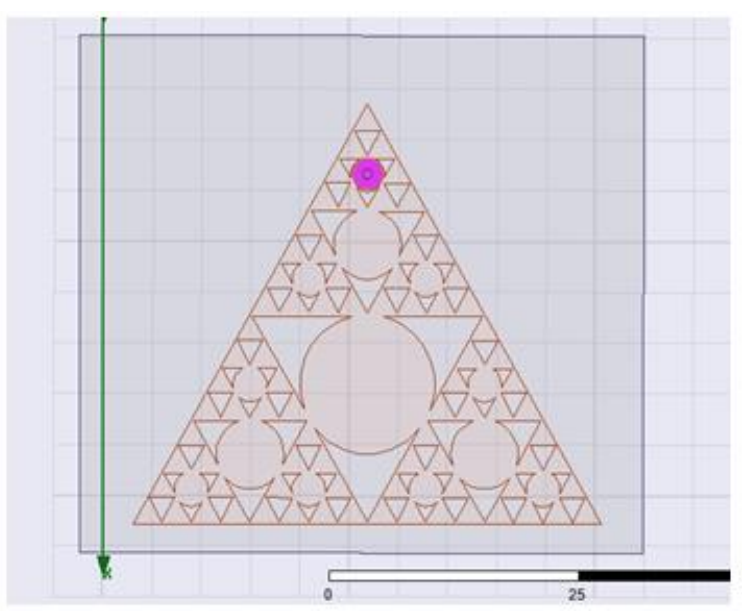

Fig:5.Triangular antenna

At first, the Feed point is placed at the centre of the larger circle as shown in figure. 5 and the inner cylinder radius $\left(\mathrm{R}_{\mathrm{i}}\right)$ of the feed is varied. The simulation results for varied radii are given below.

\section{A. RETURN LOSS:}

\section{Return loss at $\mathrm{D}=0.5 \mathrm{~mm}$}

The following graph denotes the response $S_{11}$ which shows that antenna resonates at $4.8 \mathrm{GHz}, 10 \mathrm{GHz}, 13.3 \mathrm{GHz}, 19.5$ $\mathrm{GHz}, 18.3 \mathrm{GHz}$ with return losses of $-11.1434 \mathrm{~dB},-16.91$ $\mathrm{dB},-17.0269 \mathrm{~dB},-17.38 \mathrm{~dB},-12.7446 \mathrm{~dB}$ respectively. When the inner radius is reduced to $0.5 \mathrm{~mm}$ there was an improvement in the return loss. This graph shows that the antenna resonates at multiple frequencies in $\mathrm{C}$ band, $\mathrm{X}$ band and $\mathrm{Ku}$ band.

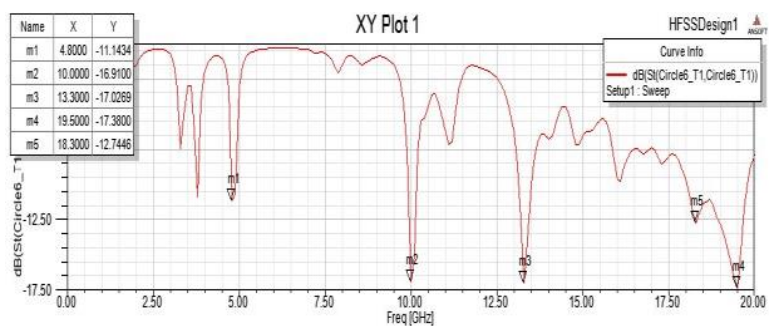

Fig:6.Return loss for fourth iteration antenna

\section{Return loss at $D=0.5 \mathrm{~mm}$ for feed position $\mathrm{d} 2$ :}

The following plot describes the response $\mathrm{S}_{11}$ which shows that antenna resonates at $4.8 \mathrm{GHz}, 10 \mathrm{GHz}, 13.3$ $\mathrm{GHz}, 19.5 \mathrm{GHz}, 18.3 \mathrm{GHz}$ with return losses of -11.1434 $\mathrm{dB},-16.91 \mathrm{~dB},-17.0269 \mathrm{~dB},-17.38 \mathrm{~dB},-12.7446 \mathrm{~dB}$ respectively. The antenna resonates at multiple bands with higher return loss which is not satisfactory. Hence the feed position of $\mathrm{d} 3$ is accepted.

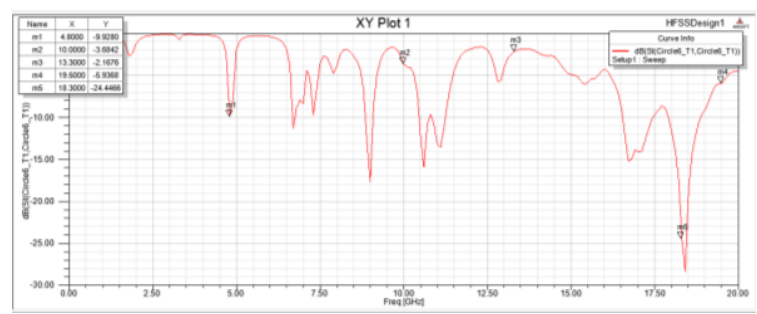

Fig:7.Return loss for iteration antenna at feed position d4 at $4.8 \mathrm{GHz}, 10 \mathrm{GHz}, 13 . \mathrm{GHz}, 19.5 \mathrm{GHz}, 18.3 \mathrm{GHz}$ frequencies are $1.333,1.3276,1.3127,1.5963,1.7671$ respectively. VSWR below the value 2 for any antenna is desirable.

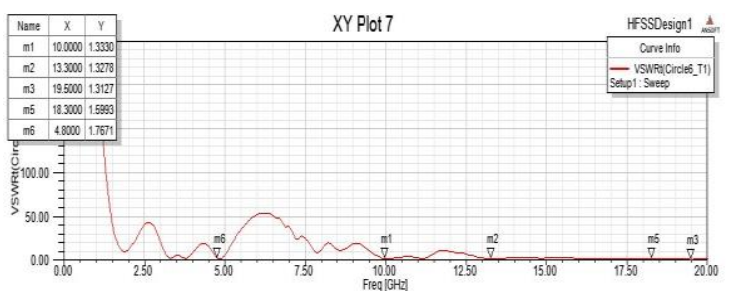

Fig:8.VSWR of fourth iteration antenna

\section{VSWR at feed position d4:}

The plot shown below describes the VSWR of the antenna at $4.8 \mathrm{GHz}, 10 \mathrm{GHz}, 13 . \mathrm{GHz}, 19.5 \mathrm{GHz}, 18.3 \mathrm{GHz}$ frequencies are 4,78, 8.05, 3.09, 1.1275, 1.9 respectively. Some of the VSWR values are above the value 2 which is not desirable for any antenna.

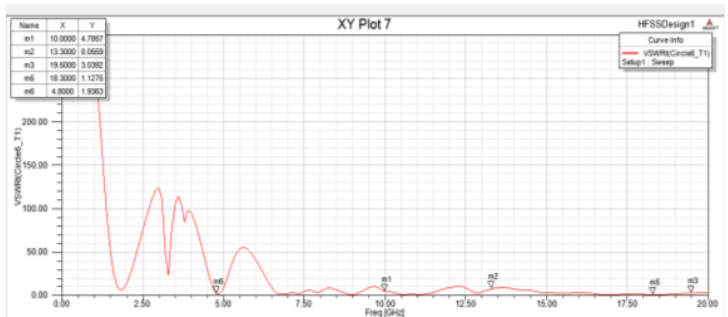

Fig:9.VSWR of fourth iteration antenna at feed position d4

Gain for the fourth iteration:

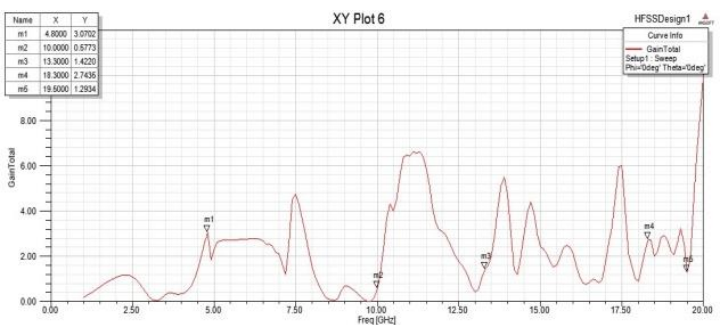

Fig:10.Gain plot for the fourth iteration antenna

The figure describes the gain values for the 4th iteration antenna at frequencies $4.8 \mathrm{GHz}, 10 \mathrm{GHz}, 13.3 \mathrm{GHz}, 18.3 \mathrm{GHz}$, $19.6 \mathrm{GHz}$ are $3.0702 \mathrm{~dB}, 0.5773 \mathrm{~dB}, 1.4220 \mathrm{~dB}, 2.7435 \mathrm{~dB}$ $1.2934 \mathrm{~dB}$. It is observed that the overall gain for the $4^{\text {th }}$ iteration antenna is double than that of the $3^{\text {rd }}$ iteration antenna.

\section{FABRICATION RESULTS}

\section{A. FABRICATED ANTENNA:}

The antenna is fabricated according to the simulation design as shown in the below figure.11. The substrate material used is FR-4 epoxy of thickness $1.6 \mathrm{~mm}$. 


\section{FRONT VIEW:}

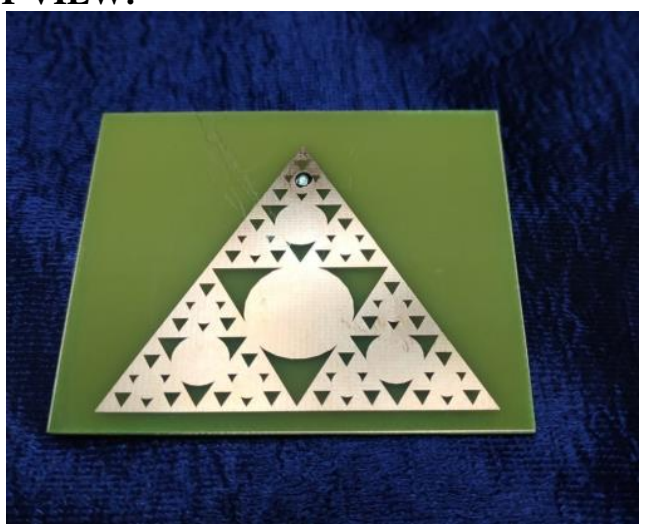

Fig:11.Photograph Sierpinski Gasket antenna

The above figure represents the front view of microstrip patch Sierpinski Gasket antenna with various iterations.

\section{BACK VIEW:}

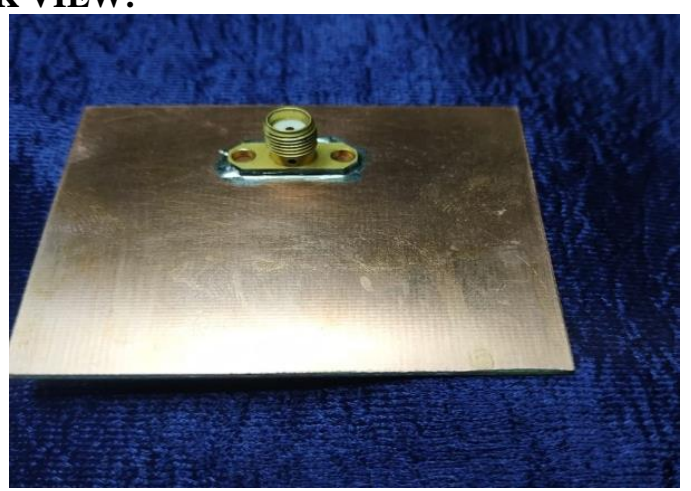

Fig:12.Photograph of Sierpinki Gasket antenna back view

The co-axial feed method is used and it can be shown in figure.12 which shows the back view of the antenna. From this the co-axial probe feeding can be seen. It can be observed that the wave port feeding is used. Soldering is used to connect the microstrip patch antenna and the coaxial feeding.

\section{B. RETURN LOSS OF FABRICATED ANTENNA:}

The fabricated antenna return loss can be shown in fig.13.

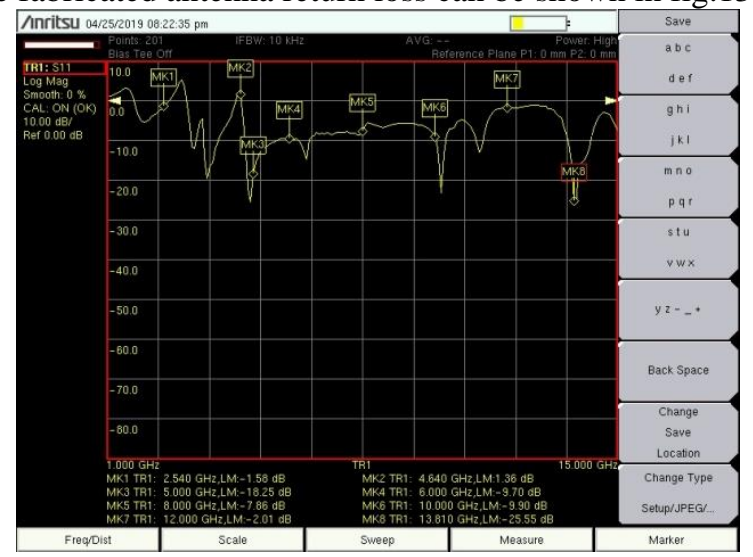

Fig:13.S-parameter of the fabricated antenna

The fabricated antenna's return loss is shown in the above fig.13, and its variation in the frequency range from 1 to 15 GHz. The fabricated antenna failed to satisfy the simulation result at $4.8 \mathrm{GHz}$ whereas it gave a better return loss of $25.55 \mathrm{~dB}$ at the frequency of $13.8 \mathrm{GHz}$ than that of the simulation results. The return loss at $10 \mathrm{GHz}$ is $-9.90 \mathrm{~dB}$. The antenna failed to satisfy at certain frequencies because of the effect of soldering during the process of fabrication.

\section{FABRICATED ANTENNA:}

The below figure shows the VSWR of the fabricated antenna and its variation in the frequency range 1 to $15 \mathrm{GHz}$. The fabricated antenna failed to satisfy the VSWR at $4.8 \mathrm{GHz}$ due to the practical issues while soldering. The VSWR values obtained at $5.000 \mathrm{GHz}, 10.00 \mathrm{GHz}, 6.00 \mathrm{GHz}$ and $13.3 \mathrm{GHz}$ are $1.26,1.97,1.28,1.11$ respectively. At these frequencies, the antenna is desirable.

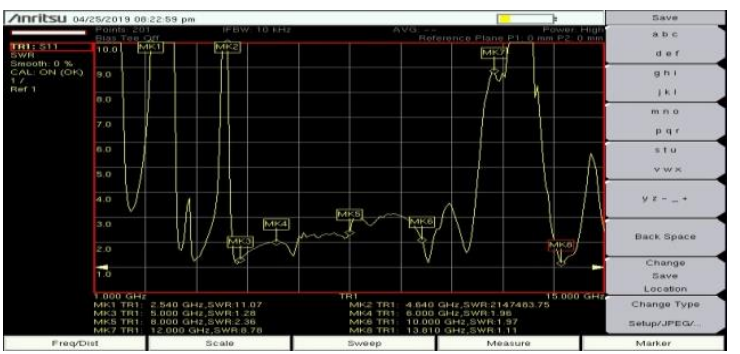

Fig:14.S-parameters of fabricated antenna

\section{COMPARISION AGAINST REPORTED DESIGNS}

TABLE-I:VSWR:

\begin{tabular}{|c|c|c|}
\hline $\begin{array}{c}\text { Resonant } \\
\text { frequencies }\end{array}$ & $\begin{array}{c}\text { Simulated } \\
\text { results }\end{array}$ & $\begin{array}{c}\text { Fabricated } \\
\text { results }\end{array}$ \\
\hline $4.8 \mathrm{GHz}$ & 1.7671 & 21.47 \\
\hline $10.00 \mathrm{GHz}$ & 1.3333 & 1.97 \\
\hline $13.3 \mathrm{GHz}$ & 1.3278 & 1.11 \\
\hline
\end{tabular}

\section{TABLE-II:RETURN LOSS:}

\begin{tabular}{|c|c|c|}
\hline $\begin{array}{c}\text { Resonant } \\
\text { frequencies }\end{array}$ & $\begin{array}{c}\text { Simulated } \\
\text { results }\end{array}$ & $\begin{array}{c}\text { Fabricated } \\
\text { results }\end{array}$ \\
\hline $4.8 \mathrm{GHz}$ & 1.7671 & 21.47 \\
\hline $10.00 \mathrm{GHz}$ & 1.3333 & 1.97 \\
\hline $13.3 \mathrm{GHz}$ & 1.3278 & 1.11 \\
\hline
\end{tabular}

From the above comparison, it can be observed that the fabrication results are well satisfied at $10.00 \mathrm{GHz}$ and 13.3 $\mathrm{GHz}$. It can be observed that good return loss of $-18.25 \mathrm{~dB}$ at $5.00 \mathrm{GHz}$ than that of $4.8 \mathrm{GHz}$ is obtained for the fabricated antenna.

\section{CONCLUSION}

A improved sierpinski gasket fractal antenna is designed upto fourth iteration for multiband applications and is simulation is done for results using HFSS software. The simulated antenna resonates at 5 different frequencies i.e. at 4.8GHz, $10 \mathrm{GHz}, 13.3 \mathrm{GHz}, 19.5 \mathrm{GHz}, 18.3 \mathrm{GHz}$ with return losses of $-11.1434 \mathrm{~dB},-16.91 \mathrm{~dB},-17.0269 \mathrm{~dB},-17.38 \mathrm{~dB}$, $12.7446 \mathrm{~dB}$ respectively and VSWR at $4.8 \mathrm{GHz}, 10 \mathrm{GHz}$, 13.GHz, $19.5 \mathrm{GHz}, 18.3 \mathrm{GHz}$ frequencies are $1.333,1.3276$, 1.3127, 1.5963, 1.7671 respectively. The designed antenna finds its applications in short range medical sensors, radar technology and in WLAN, WIMAX.

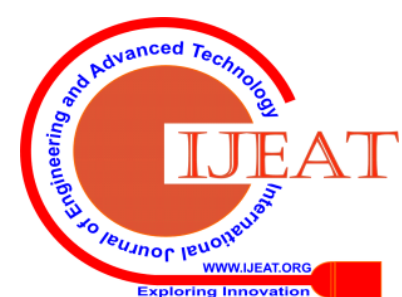




\section{REFERENCES}

1. NavreetKaur, Jagtar Singh Sivia, ManpreetKaur "Design of Modified Sierpinski Gasket Fractal Antenna for C and X-Band Applications", IEEE, Vol.1, Sep,2015.

2. Ali Fathima N. A.,Megha S., Jayarenjini N., Unni C. "Dual Polarized Microstrip Fractal Patch Antenna for S-band Applications", International Conference on Control, Communication \& Computing India, vol.1,April,2015.

3. Manasaranjannena, Kumar "Design and Optimization of Multiband F-Shaped Fractal Patch Antenna for Wireless Communication,' Second International Conference on Advances in Computing and Communication Engineering,2015.

4. Sumit Kumar, Deepak Gangwar, R. L. Yadava "Miniaturized Inverted Multiband Stacked Triangular Fractal Patch Antenna for Wireless Communication," International Conference on Signal Processing and Integrated Networks, Vol.1,Aug,2014

5. SanjeevYadav,Pushpanjali Jain, RuchikaChoudhary "A Novel Approach of Triangular Circular Fractal Antenna,IEEE,Vol.1,July,2014.

6. CarlesPuneteBaliarda"Design and Analysis of Fractal Antennas based on Koch and Sierpinski Fractal Geometries",IJAREEIE,Vol.12,Issue 6,June,2013.

7. Kulbir Singh, VinitGrewal and Rajiv Saxena "Fractal Antennas: A Novel Miniaturization Technique for Wireless Communications,'IJRTET,Vol.2,Nov,2009.

8. Sachendra N. Sinha,Manish Jain "A Self-Affine Fractal Multiband Antenna," IEEE antennas and wireless propagation letters, vol. 6, 2007.

9. V P Sainet, Antenna Theory Analysis and Design, 2nd ed, Wiley India (p.) Ltd. 2007.

10. Konda R B, Pushpanjali G M, Mulgi S N, Satnoor S K, Hadalgi P M \&Hunagund P V, Design of wideband and multiband microstrip array antennas, Indian J Radio Space Phys, Vol.35,2005.

11. Hyok Song J \&MarekBailkowski," E, Ku-Band $16 \times 16$ planar array with aperture-coupled microstrip patch elements,'IEEE Antenna Propag Mag(USA),Vol.40,1998

12. R. J. Mailloux, J. F. McIlvenna, and N. P. Kernweis, "Microstrip Array Technology," IEEE Trans. Antennas Propag., Vol. AP-29, No.1, pp. 25-37, January 1981.

\section{AUTHORS PROFILE}

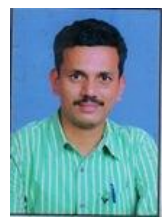

Mr.Ch.Raghavendra obtained his B.E Degree in Electronics and Communications Engineering from Anna University, Chennai in 2007 and M.Tech Degree in Communication and Signal Processing, from ANU Guntur, in 2011. Presently he is working as Assistant professor at V.R.Siddhartha Engineering College, Vijayawada.

Mr.Ch.Raghavendra has 13 years of teaching experience, and has about 10 technical publications in various International and National Journals and Conferences to his credit. He received grants from DLRL in the area of Shared Aperture Antennas. His fields of interest include Smart Antennas, Antenna Beam forming Algorithms, Analysis of Microwave and Radar.

K.Vijay krishna pursuing B.Tech in Electronics and Communication Engineering from V.R.Siddhartha Engineering College, Vijayawada

B.Pavan kalyan pursuing B.Tech in Electronics and Communication Engineering from V.R.Siddhartha Engineering College, Vijayawada 